Project Report

\title{
Microwave Satellite Measurements for Coastal Area and Extreme Weather Monitoring
}

\author{
Ferdinando Nunziata ${ }^{1, *(\mathbb{C}}$, Xiaofeng $\mathrm{Li}^{2}{ }^{\circledR}$, Armando Marino ${ }^{3}$, Weizeng Shao ${ }^{4}$, Marcos Portabella ${ }^{5}($, \\ Xiaofeng Yang ${ }^{6}\left(\mathbb{D}\right.$ and Andrea Buono ${ }^{1}$ (i)
}

1 Engineering Department, Parthenope University of Naples, 80143 Naples, Italy; andrea.buono@uniparthenope.it

2 Key Laboratory of Ocean Circulation and Waves, Institute of Oceanology, Qingdao 266071, China; xiaofeng.li@ieee.org

3 Department of Biological and Environmental Sciences, University of Stirling, Stirling FK9 4LA, UK; armando.marino@stir.ac.uk

4 College of Marine Science and Technology, Zhejiang Ocean University, Zhoushan 316000, China; shaoweizeng@zjou.edu.cn

5 Department of Physical Oceanography, Institute of Marine Sciences, CSIC, 08003 Barcelona, Spain; portabella@icm.csic.es

6 State Key Laboratory of Remote Sensing Science, Aerospace Information Research Institute, Beijing 100101, China; yangxf@radi.ac.cn

* Correspondence: ferdinando.nunziata@uniparthenope.it

Citation: Nunziata, F.; Li, X.; Marino, A.; Shao, W.; Portabella, M.; Yang, X.; Buono, A. Microwave Satellite Measurements for Coastal Area and Extreme Weather Monitoring. Remote Sens. 2021, 13, 3126. https://doi.org/ $10.3390 /$ rs13163126

Academic Editor: Weimin Huang

Received: 29 July 2021

Accepted: 4 August 2021

Published: 6 August 2021

Publisher's Note: MDPI stays neutral with regard to jurisdictional claims in published maps and institutional affiliations.

Copyright: (c) 2021 by the authors. Licensee MDPI, Basel, Switzerland. This article is an open access article distributed under the terms and conditions of the Creative Commons Attribution (CC BY) license (https:// creativecommons.org/licenses/by/ $4.0 /)$.

\begin{abstract}
In this project report, the main outcomes relevant to the Sino-European Dragon-4 cooperation project ID 32235 "Microwave satellite measurements for coastal area and extreme weather monitoring" are reported. The project aimed at strengthening the Sino-European research cooperation in the exploitation of European Space Agency, Chinese and third-party mission Earth Observation (EO) microwave satellite data. The latter were exploited to perform an effective monitoring of coastal areas, even under extreme weather conditions. An integrated multifrequency/polarization approach based on complementary microwave sensors (e.g., Synthetic Aperture Radar, scatterometer, radiometer), together with ancillary information coming from independent sources, i.e., optical imagery, numerical simulations and ground measurements, was designed. In this framework, several tasks were addressed including marine target detection, sea pollution, sea surface wind estimation and coastline extraction/classification. The main outcomes are both theoretical (i.e., new models and algorithms were developed) and applicative (i.e., user-friendly maps were provided to the end-user community of coastal area management according to smart processing of remotely sensed data). The scientific relevance consists in the development of new algorithms, the effectiveness and robustness of which were verified on actual microwave measurements, and the improvement of existing methodologies to deal with challenging test cases.
\end{abstract}

Keywords: microwave satellites; multipolarization; multifrequency; oceans; coastal areas; coastline; sea wind field; ocean pollution; ships

\section{Introduction}

In this paper the main scientific achievements stemming from the Dragon-4 cooperation programme are discussed. The main scientific goal of the project relied on the exploitation of microwave satellite measurements to generate innovative added-value products to observe coastal areas also under extreme weather conditions. The methods/products developed under the Dragon- 4 cooperation were based on a deep and fruitful cooperation between Chinese and European (including Italy, UK, Spain, France and Netherlands) partners that called for complementary expertise. Moreover, young faculty as well as Master's and Ph.D. students contributed to the understanding of the phenomena under study, i.e., coastal water pollution, coast erosion, ship and metallic target detection 
and typhoon/cyclone monitoring. They also contributed to the development of new and effective methods to move from remotely sensed microwave measurements-mainly collected by the Synthetic Aperture Radar (SAR) and the scatterometer operated by European Space Agency (ESA), ESA third-party and Chinese missions-to added-value products as thematic maps.

This research project provides important outcomes that can be summarized as follows: (a) promoting an "intelligent", i.e., physically-based, use of remotely sensed microwave measurement for generating added-values products: coastal water pollution, coast erosion, ship and metallic target detection, typhoon monitoring; (b) developing new models/methods to deal with multipolarization SAR measurements for costal area observation; (c) promoting the cooperation between Chinese and European partners by taking full advantage of their respective expertise. This project aimed at filling the gap with respect to existing literature by taking full advantage of multifrequency/multipolarization information and by integrating the information extracted by different satellite sensors with independent information provided by ancillary sources and in situ measurements. Accordingly, more efficient and accurate algorithms were developed to address specific tasks, while existing methods were cross-validated even under challenging test cases.

The aforementioned added-value products were generated by transforming microwave measurements into end-user friendly products through a tailored modelling of the phenomenon under study. Coastal water pollution, coastal erosion, metallic target observation and sea surface scattering under extreme conditions were mainly addressed using SAR measurements. Single-, dual-, full- and compact-polarimetric SAR architectures were exploited. In particular, single-polarization and polarimetric methods were developed to generate added-value products that consist of risk/vulnerability maps, targets at sea maps and pollutants maps and cyclone/typhoon monitoring. This latter task was addressed using a multisensor approach based on the exploitation of SAR and scatterometer measurements together with data assimilation models and ancillary buoys/model information.

The project's outcomes were disseminated through a number of publications submitted to the periodic Dragon 4 annual symposia and to peer-reviewed scientific journals. The fruitful cooperation stemming from this Dragon- 4 cooperation programme is being advanced and strengthened in the Dragon-5 cooperation programme.

\section{Project, Subprojects, EO and Other Data Utilization}

The project exploited microwave satellite remotely sensed measurements to generate innovative added-value products to observe coastal areas also under extreme weather conditions. The following thematic areas were addressed: coastal water pollution, coast erosion, ship and metallic target detection and typhoon monitoring. In this paper, an overview of the activities undertaken by European (EU) and Chinese research groups is presented and showcased through some meaningful experiments.

\subsection{List of Subprojects and Teaming}

- $\quad$ Subproject 1, "SAR-based coast observation (SARCO)", was chaired by Prof. Ferdinando Nunziata and Prof. Xiaofeng Li, who supervised the activities of a team composed of EU (Prof. Guido Benassai and Dr Andrea Buono from the University of Naples Parthenope (Italy), Prof. Roman Fablet from Telecom Bretagne (UK) and Dr Salvatore Stramondo and Dr Antonio Montuori from the Italian National Institute of Geophysics and Volcanology (Italy)) and Chinese (Dr Xianwen Ding, Dr Yongliang Wei, Dr Tan Yu, Ms. Yu Liu and Ms. Bingqing Liu from the Shanghai Ocean University) scientists. The subproject dealt with the observation of coastal areas using multipolarization SAR, and the main activities can be summarized as follows: (1) integrated Coastal Area Management using SAR-based wind information; (2) intertidal flat monitoring; (3) sea oil slick observation. All the activities shared a similar rationale, i.e., developing new and effective methods to deal with the aforementioned applications using multipolarization SAR measurements. 
- Subproject 2, "Ship and coastal water pollution observation with polarimetric SAR architectures (SCoPeSAR)", was chaired by Dr Armando Marino and Dr Weizeng Shao, who supervised a team composed of EU (Dr Stian Normann Anfinsesn from the Arctic University of Norway (Norway), Dr Raffaella Guida from the University of Surrey (UK), Dr Gerard Margarit from GMV (Spain), Prof. Maurizio Migliaccio from the University of Naples Parthenope (Italy) and Dr Marc Pradas from the Open University (UK)) and Chinese (Dr Qing Xu from the Hohai University, Dr Jian Sun from the Ocean University of China, Dr Chao Chen and Dr Lina Cai from the Zhejiang Ocean University and Mr Tao Zhang from the Shanghai Ocean University) scientists. The subproject dealt with the detection of ships and microplastic pollution at sea using polarimetric SAR measurements, and the main activities can be summarized as follows: (1) development of new polarimetric detectors to observe ships in full- and dual-polarimetric SAR imagery; (2) analysis of the sensitivity of SAR measurements to microplastic pollutants in the ocean; (3) typhoon monitoring using SAR measurements collected by the Chinese Gaofen-3 SAR.

- Subproject 3: "Sea-surface high-wind experiments with long-range (satellite) observations using numerical geophysical methods (SHENLONG)" was chaired by Dr Marco Portabella and Prof. Xiaofeng Yang, who supervised a team composed of EU (Dr Ad Stoffelen from the Royal Netherlands Meteorological Institute (The Netherlands), Dr Alexis Mouche from the French Institute for the Sea Exploitation Research (France), Dr Giuseppe Grieco from the Italian Space Agency (Italy), Dr Wenming Lin from the Institute of Marine Sciences (Spain) and Dr Franco Fois from the Delft University of Technology (The Netherlands)) and Chinese (Prof. Ziwei Li, Dr Guihong Liu, Dr Yang Yu, Mr Yanlei Du and Ms. Di Dong from the Chinese Academy of Sciences) scientists. The subproject dealt with the analysis of winds under nominal and extreme weather conditions, and it addressed both the estimation of wind using microwave SAR and scatterometers and the exploitation of SAR-based winds in numerical prediction models related to tropical cyclones. The main activities can be summarized as follows: (1) estimating wind speed by SAR imagery using a new spectral method; (2) data assimilation of remotely sensed measurements collected by SAR and scatterometer into numerical prediction models for typhoon monitoring purposes.

\subsection{Description and Summary Table of EO and Other Data Utilized}

The satellite remote sensing data used to carry on the aforementioned activities refer to SAR and scatterometer missions. In particular, 1561 SAR scenes and 99 scatterometer data, for a total of 1660 EO measurements (see Figure 1), were used. The SAR data set consisted of:

- 4 scenes and 10 scenes collected by the L-band PalSAR-1 (Phased Array type L-band SAR) and PalSAR-2, from the Japanese Aerospace Agency (JAXA) ALOS-1 (Advanced Land Observing Satellite) and ALOS-2 missions, respectively;

- 645 scenes collected by the C-band ESA Sentinel-1 mission, 9 scenes collected by the C-band Canadian Space Agency (CSA) Radarsat-2 mission and 759 scenes collected from the C-band Gaofen-3 China National Space Administration (CNSA) mission;

- 112 scenes collected by the German Aerospace Agency (DLR) X-band TerraSAR-X mission and 20 scenes collected by the Italian Space Agency (ASI) Cosmo-SkyMed constellation.

When dealing with SAR data, the research activities on sea surface analysis were performed using:

- TerraSAR-X: 6 dual-pol (HH+VV) StripMap mode and 3 VV-pol ScanSAR mode SAR scenes;

- $\quad$ Sentinel-1: 355 VV-pol StripMap mode, 26 dual-pol (VV+VH, HH+HV) Interferometric Wide Swath mode and 33 VV-pol Interferometric Wide Swath mode SAR scenes;

- Gaofen-3: 642 wave mode, 83 quad-pol mode, 14 co-pol StripMap mode, 5 dual-pol $(\mathrm{VV}+\mathrm{VH})$ Global Observation and ScanSAR wide mode, 8 dual-pol Extra Wide and 
Interferometric Wide Swath mode, 7 VH-pol Global Observation and ScanSAR wide mode SAR scenes.

- Radarsat-2: 4 quad-pol mode SAR scenes;

- ALOS PalSAR-1: 4 quad-pol mode SAR scenes;

- ALOS PalSAR-2: 10 quad-pol mode SAR scenes;

Research activities on metallic target detection were performed using:

- $\quad$ TerraSAR-X: 16 dual-pol (HH+VV, HH+HV, VV+VH)-pol StripMap mode, 8 VV-pol Wide ScanSAR mode and $5 \mathrm{HH}$-pol Wide ScanSAR mode SAR scenes;

- $\quad$ Sentinel-1: 9 dual-pol (VV+VH) Interferometric Wide Swath mode SAR scenes;

- $\quad$ Radarsat-2: 4 quad-pol mode SAR scenes.

Research activities on marine pollution were performed using:

- $\quad$ Sentinel-1: 175 dual-pol (VV+VH) Extra Wide Swath mode SAR scenes;

- COSMO-SkyMed: 10 dual-pol (HH+VV) PingPong mode and 10 VV-pol StripMap mode SAR scenes;

- $\quad$ TerraSAR-X: 66 dual-pol (HH+VV) StripMap mode, 2 VV-pol ScanSAR mode and 7 VV-pol StripMap mode SAR scenes.

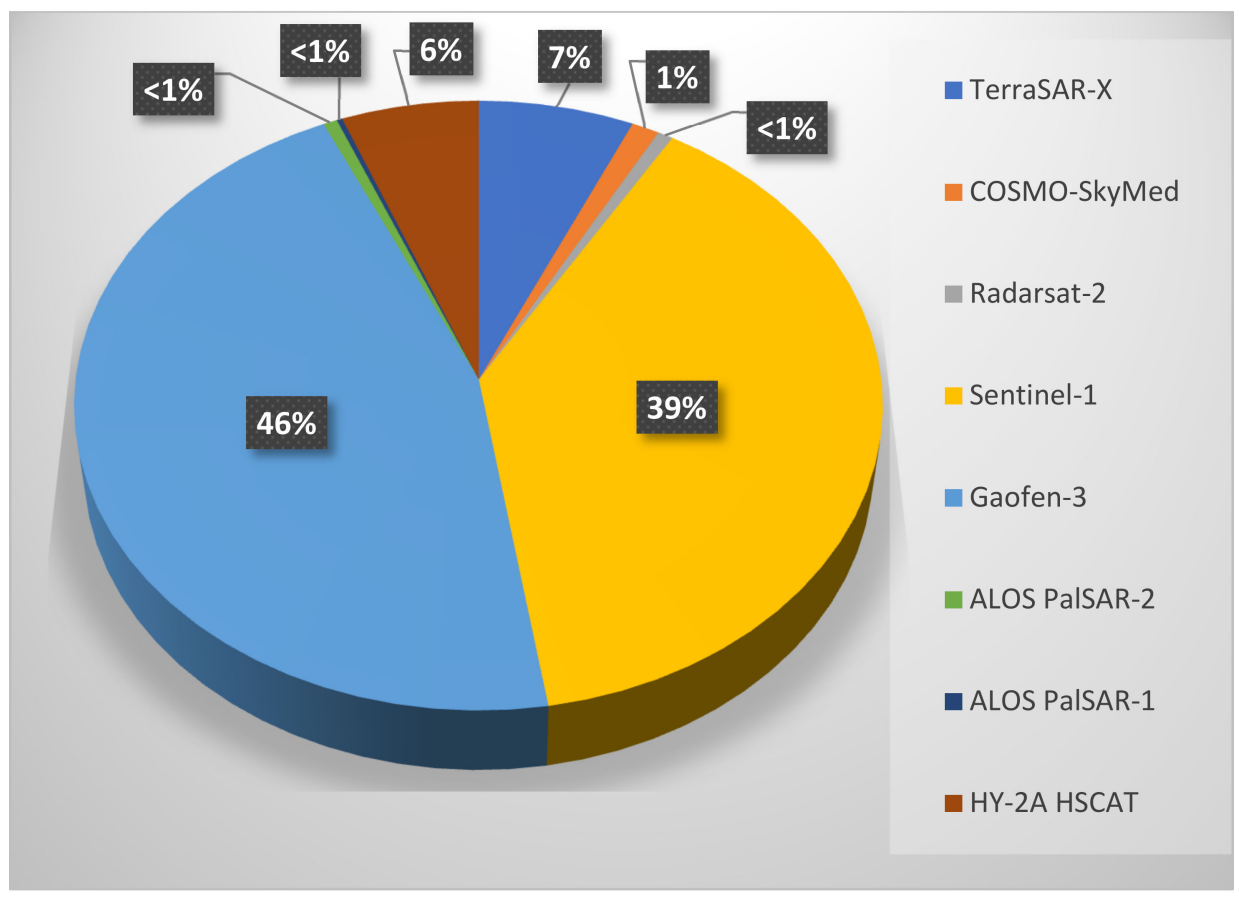

Figure 1. EO data collected by SAR (1561) and scatterometer (99) instruments.

Research activities on coastline extraction/classification were performed using:

- $\quad$ Sentinel-1: 47 dual-pol (VV+VH) Interferometric Wide Swath mode SAR scenes;

- $\quad$ Radarsat-2: 3 quad-pol mode SAR scene.

The scatterometer data set consisted of ocean winds obtained by the Ku-band scatterometer HSCAT onboard of the CNSA (China National Space Administration) second generation ocean observation/monitoring HY-2A satellite. HSCAT provides sea surface wind vectors on a $25 \mathrm{~km} \times 25 \mathrm{~km}$ spatial grid with a root mean square error (RMSE) below $2 \mathrm{~m} / \mathrm{s}$ and $25^{\circ}$ for speed and direction, respectively.

Additional remotely sensed data from airborne platforms were considered. The stepped multifrequency microwave radiometer (SFMR) onboard the National Oceanic and Atmospheric Administration (NOAA) WP-3D and U.S. Air Force aircraft was used to measure along-track surface winds in hurricanes up to $70 \mathrm{~m} / \mathrm{s}$ with relatively high spatial 
(about $120 \mathrm{~m}$ ) and temporal $(1 \mathrm{~Hz}$ ) resolutions. The NASA/JPL UAVSAR provided fine resolution quad-polarimetric SAR data.

The ancillary data set used for validation consisted of in situ measurements:

- Global Positioning System (GPS) samples to detect the coastline location;

- mooring buoys to obtain local sea wind field information;

- Automatic Identification System (AIS) data to detect cooperative targets' locations;

- dropwindsonde, an expendable weather reconnaissance device deployed over the ocean from aircraft that includes a GPS receiver as well as pressure, temperature and humidity sensors to capture atmospheric profiles and thermodynamic data during storm conditions.

External information as forecasting data from assimilated models. i.e., ocean wind fields from the European Centre for Medium-range Weather Forecasting (ECMWF) and tropical cyclone/storm observations (10 $\mathrm{m}$ height wind vector, maximum wind speed and its corresponding azimuth, hurricane central pressure) provided by the NOAA service based on the HRD Real-time Hurricane Wind Analysis System (HWIND), a distributed system that ingests real-time land-, sea-, space- and airborne platforms' measurements, were also exploited for reference/validation purposes.

\section{Subprojects' Research and Approaches}

\subsection{SARCO-SAR-Based Coast Observation}

3.1.1. Research Aims

The research activities consisted of developing new algorithms and new methodologies to exploit multipolarization SAR measurements in the following thematic domains:

- Mapping the inland cover to provide information about land usage, i.e., urban and industrial areas, tideland, water bodies, vegetation and sandy beaches, etc. This can support the detection of changes and the effects of natural and anthropogenic processes as deforestation, urbanization, etc.

- Monitoring man-made sea targets including offshore wind farms, oil and gas fields, aquaculture, etc. This can support effective observation of economic activities and critical infrastructures.

- Extraction of the shoreline position and its dynamics. This can support the assessment of the effects associated with processes such as erosion accretion and relative sea level rise.

We demonstrated that, in all the thematic domains, polarimetric information offers key benefits in generating robust and effective added-value products.

\subsubsection{Research Approach}

The research approach consisted of developing or using methods that, based on a combination of parameters derived from polarimetric observables, allowed a robust and effective retrieval of the geophysical parameters of interest and the generation of addedvalue products. Two approaches are hereinafter showcased to demonstrate the proposed theoretical rationale:

1. detection of wind turbines in a harsh environment;

2. shoreline extraction and generation of risk maps.

When dealing with the detection of wind turbines, two scattering-based approaches were adopted: the polarimetric notch filter (PNF) proposed in [1] and a change detector based on the polarimetric matched filter (PMF) [2]. The PNF exploited the polarimetric coherence to enhance the backscattering differences between the targets and the surrounding sea clutter, i.e., the targets were considered as anomalies with respect to the background. Hence, the polarimetric coherence between the sea clutter and its perturbed version can be defined as:

$$
\gamma=\frac{1}{\sqrt{1+\operatorname{RedR} \frac{P_{S}}{P_{T}}}},
$$


where the parameter RedR is a tuning parameter that allows rescaling the clutter distribution to avoid numerical errors in the computation of the detection mask [1] and $P_{S}$ and $P_{T}$ are the backscattering power associated to the sea surface and the target, respectively.

The PMF dealt with the optimization of the target-to-clutter power ratio using a single polarimetric SAR image. This method was based on the scattering mechanisms $\omega_{\max }$ that maximize the following ratio:

$$
\rho=\frac{\omega^{\dagger} C_{r} \omega}{\omega^{\dagger} C_{i} \omega}
$$

where $C_{r}$ and $C_{i}$ are the covariance matrices that describe the reference scenario (i.e., a sea surface region of interest) and the study area (i.e., the whole SAR image), respectively, $\omega$ is the projecting vector and + stands for complex conjugate transpose. To search for $\omega_{\max }$, an optimization problem was addressed that can be formulated according to the Lagrangian method [3]. The latter was applied to the quadratic form $\omega^{\dagger} C_{C D} \omega$, where the change matrix $C_{C D}$ is given by:

$$
C_{C D}=C_{i} C_{r}^{-1}
$$

Hence, the following eigenvalue problem was obtained:

$$
C_{C D} \omega=\lambda_{i} \omega,
$$

with $\lambda_{i}$ being the $N$ (which is the polarimetric information dimensionality, e.g., 2 if dual-polarimetric SAR data are considered) real and positive eigenvalues that maximize/minimize the contrast between the polarimetric backscattering of the target with respect to the sea clutter. In this study, the sum of the $N$ eigenvalues was considered as the feature to detect anomalies with respect to the sea surface, since it was expected to be sensitive to the different polarimetric scattering signatures that characterize metallic targets such as wind turbines and sea clutter.

The main novelties associated to this research approach consisted of using state-ofthe-art approaches to test the performance of these algorithms in detecting metallic targets in a very harsh environment, namely a large intertidal flat area. The performance of the methods and their superiority with respect to single-polarization SAR metrics were discussed using an objective metric, namely the Receiver Operating Characteristic (ROC) curve, and a data set that consisted of both C- and X-band multipolarization SAR scenes.

When dealing with shoreline extraction and risk map generation from polarimetric SAR imagery, the following metrics were considered: the average product between the coand cross-polarized scattering amplitudes $[4,5]$ and the scattering components obtained from Freeman-Durden model decomposition [6]:

$$
\begin{gathered}
r=\left\langle\left|S_{X X}\right| \cdot\left|S_{X Y}\right|\right\rangle, \\
T=P_{S} T_{S}+P_{D B} T_{D B}+P_{V} T_{V} .
\end{gathered}
$$

In (5), $S_{X Y}$ with $\{X, Y\} \in\{H, V\}$ is the complex scattering amplitude, while $|\cdot|$ and $\langle\cdot\rangle$ stand for modulus and ensemble average. In (6), the quad-polarization coherency matrix $T$ is decomposed into three coherency matrices associated to the elementary scattering mechanisms, i.e., surface $\left(T_{S}\right)$, double bounce $\left(T_{D B}\right)$ and volume $\left(T_{V}\right)$, scattering, whose backscattering powers are $P_{S}, P_{D B}$ and $P_{V}$, respectively.

For shoreline extraction purposes, only $r, P_{S}$ and $P_{V}$ were considered, as these features were expected, depending on sea state conditions and coastal morphology, to emphasize the land/sea backscattering contrast.

The methodology adopted to extract the coastline mainly consists of five steps:

1. Preprocessing, including radiometric calibration, geocoding and speckle filtering.

2. Evaluation of the metrics in (5) from dual- and the quad-polarization SAR data and in (6) from quad-polarization ones. 
3. Generation of the land/sea binary image according to a global threshold Constant

False Alarm Rate (CFAR) applied on $r$.

4. Postprocessing, including morphological filtering to remove artifacts and fill in holes.

5. Edge detection, to extract the continuous coastline from the refined binary image.

Further investigation was devoted to the first and the last points, where the performance of local (boxcar, Lee) and nonlocal (patch-based) speckle filters as well as of Sobel and Canny edge detector kernels was assessed.

For risk map generation purposes, the peculiar scattering information relevant to the land cover along the coast was extracted from SAR images to identify potentially risky areas. Hence, in this study, a supervised classification based on the three FreemanDurden decomposition scattering components (6) was applied, since those components were expected to identify the different coastal scenarios, i.e., urban areas, vegetation and bare soils, associated to different risk levels.

The main novelties associated with this research approach was generating addedvalue products that consisted of the extracted coastline and the classification of the inland area near the extracted coastline using a single multipolarization scene. Hence, a userfriendly map that includes the extracted coastline and the risks associated to the different areas in the proximity of the extracted coastline is provided. Risk levels are estimated according to the land-use classification.

\subsection{SCoPeSAR-Ship and Coastal Water Pollution Observation with Polarimetric SAR Architectures}

\subsubsection{Research Aims}

The goal was to understand the benefit of multipolarization SAR in the observation of oil platforms at sea and marine plastic pollution. The main scientific outcomes can be split into two parts:

1. With respect to the detection of oil rigs, we demonstrated how innovative methodologies can use multipolarization diversity to improve the detection rate against the incidence angle with respect to single-polarization metrics.

2. With respect to water quality, we tackled the pressing problem of water pollution including emerging pollutants such as plastic. In the long run, this product will benefit from multipolarization SAR measurements and ancillary optical and in situ observations. In this work we focused on microplastic in the gyres as well as identifying possible source of oil pollution as oil rigs.

The methodologies investigated in this project are listed as follows:

- For target detection, all the works investigated the use of polarimetric SAR. This includes quad-polarimetric images, but also Sentinel-1 dual polarimetric images. Novel methodologies were developed and compared to the current state of the art to evaluate the benefits of (i) novel ways of processing data and (ii) the addition of extra polarization channels.

- $\quad$ Regarding water quality, the polarimetric sea surface backscattering with and without pollutant was modelled in physical terms by exploiting SAR data. The aim was to detect areas of high concentration of microplastic with respect to the surrounding sea and map the dampening properties of the surfactant produced by the plastic.

\subsubsection{Research Approach}

Polarimetric SAR was demonstrated to significantly improve the performance of target detectors. Polarimetry is very useful because a different polarimetric behaviour is expected between targets and the sea surface. Due to the presence of complex structures, backscattering from artificial targets is often various, including single-bounce, doublebounce and multiple-bounce returns. By analysing the different scattering mechanisms between sea surface and ships, many excellent works have been done on ship detection. In [7], the reflection symmetry (RS) properties of the sea and artificial targets were effectively used to detect ships. In [1], a new scheme was further constructed, called the geometrical 
perturbation-polarimetric notch filter method (GP-PNF), separating ships and sea in the polarimetric target complex space. Those works were advanced by this research and the following methodologies were developed:

In [8], we developed an enhanced version of the PNF where a Principal Component Analysis (PCA) is performed before applying the PNF. This allows aligning a basis to one where the sea clutter is most separable and then uses that basis for the following analysis. This used dual-polarimetric data from Sentinel-1.

In [9], we considered the challenge of detecting metallic artificial platforms. We modelled the scattering mechanisms produced by oil platforms. We then proceeded by applying different detectors to evaluate which one could best separate the sea clutter from the artificial platform.

In [10], we moved our attention to wind turbines. Again, we first modelled the polarimetric backscattering and then tested different detectors. In particular, we tried the Polarimetric Match Filter and some other novel optimizations proposed by the authors.

In [11], we moved our attention to a natural target, mud flats. These are very dynamic environments, and it is important to understand their changes in order to better model geomorphological phenomena such as erosion. In this work we applied a novel classification strategy based on an optimization that was recently proposed by the authors.

In addition, a recent advance in the context of the observation of marine pollution was related to the understanding of the ability of SAR measurements to observe or to be a proxy of marine plastic pollution.

In $[12,13]$, we attempted the very challenging topic of detecting microplastic in the ocean. We hypothesized that microplastic is colonized by microbes, and because of their metabolism, these microbes produce surfactants that can dampen the capillary and short gravity waves. Using Sentinel-1 we observed a large presence of surfactants in the gyres of Atlantic and Pacific oceans, which was not related to high level of chlorophyll-a. This preliminary research activity is still an ongoing work that we are carrying out under the framework of another ESA project.

The main novelties associated to this research approach consisted of both advancing the state of the art related to the detection of metallic targets at sea using multipolarization SAR measurements and pioneering a new study on the ability of SAR measurements to provide complementary information to assist the observation of marine pollutants.

\subsection{SHENLONG—Sea-Surface High-Wind Experiments with Long-Range (Satellite) Observations Using Numerical Geophysical Methods}

\subsubsection{Research Aims}

The main objectives of this research activity can be summarized as follows: (i) developing models to simulate the multifrequency and multipolarization sea surface backscattering under high wind and moist convection conditions; (ii) developing methods to monitor tropical cyclones from multiple active microwave remote sensed observations.

The outcomes of this project can be summarized as follows:

1. Improvement of both the physical and empirical simulation accuracy of polarized sea surface backscattering. The new models give better results under high winds.

2. State-of-the-art wind verification and objective validation tools to thoroughly assess the SAR wind retrieval quality under high wind conditions.

3. Monitoring of tropical cyclone locations, as well as tropical cyclone surface winds, centre pressure, rain bands and other parameters, from multisensors, including multipolarization SARs, and other microwave EO data.

\subsubsection{Research Approach}

Near-sea-surface wind field observation is of paramount importance in a number of meteorological and oceanographic applications: wind is the major factor responsible for environmental threats including coastal erosion, climate change, threats to marine life and so on. Satellite microwave remote sensing is a key source of information to provide reliable 
and up-to-date mesoscale wind speed maps routinely from a main sea surface wind data source. Within this context, the main instrument is the scatterometer, i.e., a real aperture radar that exploits multiple radar backscatter measurement to estimate with a remarkable accuracy the sea surface wind vector on a spatial grid of the order of tenths of kilometres. The underpinning rationale consists of exploiting the relationship between radar backscatter intensities and their statistical properties and sea surface roughness through a semiempirical Geophysical Model Function (GMF) that converts radar observables into wind information.

To provide wind field estimates on a finer resolution scale, SAR is the mandatory choice. A number of approaches have been proposed that modify/extend the C-band scatterometer GMF to the C-band SAR case and are grouped under the umbrella of CMOD GMFs, with the newest one being CMOD7.

In this piece of research two research activities are detailed:

1. Extension and analysis of the azimuth cutoff procedure for sea surface wind speed retrieval under extreme weather conditions.

2. The development of the Asymmetric Hurricane Parametric Model based on cross-pol SAR observations.

With respect to the azimuth cutoff procedure, an alternative approach was proposed and discussed that consists of exploiting peculiar SAR imaging of the sea surface [14,15]. The approach, which is termed an azimuth cutoff procedure, is based on the Doppler misregistration in azimuth that is induced by gravity wave orbital motion. This issue is the major cause of distortion in the SAR imaged spectrum and of a strong cutoff in the azimuthal direction: this is the azimuth cutoff. In literature, the azimuth cutoff method has been used to retrieve wind speed, and several studies have been carried out to analyse the dependence of the azimuth cutoff wavelength, namely $\lambda_{c}$, on sea surface parameters. In particular, there is a linear relationship between the azimuth cutoff wavelength and sea surface geophysical parameters such as wind speed and significant wave height. The retrieval of $\lambda_{c}$ from SAR imagery consists of the following key steps:

1. partitioning the SAR image into square tiles;

2. estimating the autocorrelation function $(A C F)$ by evaluating the inverse fast Fourier transform (IFFT) of the power density spectrum computed for each tile;

3. mitigating the ACF peak caused by speckle noise by applying a median filter;

4. evaluating $\lambda_{c}$ as follows [15]:

$$
\lambda_{c}=\sqrt{2 \pi \sigma},
$$

where $\sigma$ is the standard deviation of the Gaussian distribution that best fits the estimated ACF;

5. estimating sea surface wind speed at $10 \mathrm{~m}$ above sea level $(U)$ according to [16]:

$$
\lambda_{c}=a+b U
$$

where $a$ and $b$ are data-related coefficients to be determined.

Recently, the azimuth cutoff approach has been improved to deal even with high wind speed regimes, e.g., extreme weather conditions. The key issues that allow extending the method to high wind regimes concern the optimization of the parameter setting with respect to pixel spacing, box size and the homogeneity of the SAR imagery. Once the surface wind distribution has been derived from SAR observations, one can estimate the intensity of tropical cyclones. The numerical parametric model of tropical cyclone wind fields has been a widely accepted approach for estimating wind speeds to predict and assess typhoon/hurricane risk [17]. Parametric models use some physically meaningful parameters to represent the cyclone system's physical quantities, such as maximum velocity, pressure, wind radii, etc. These models are simple with low computational cost. However, the existing models were developed based on limited in situ observations and poorly presented the asymmetric structure of tropical cyclones [18]. Fortunately, recent studies 
have shown that spaceborne SAR imagery can be used to obtain high-resolution and accurate wind information under tropical cyclone conditions [19]. Thus, in this study, a new parametric tropical cyclone model is proposed to simulate the asymmetric wind speed distribution of tropical cyclones. Parameters of the new model were extracted by using SAR images and their derived sea surface wind maps. The proposed model was also tested and verified with best-track reanalysis data and airborne measurements.

With respect to the use of SAR measurements to model hurricane asymmetries, SAR has been proven to be a useful tool in monitoring hurricane structure and intensity [19]. Cross-polarization SAR can provide high-resolution and accurate sea surface wind observations of hurricanes $[20,21]$. These properties yield the opportunity to investigate the details of hurricane structure. The mathematical simulation of hurricanes is a widely accepted approach for estimating wind speed to design structures and assess hurricane risk [17]. Generally, parametric models are abstract descriptions of a hurricane meteorological system using some physically meaningful parameters, such as the maximum wind speed, which represents the intensity of hurricanes, and the parameter $B$ in the Holland model, which represents the shape of hurricanes [22]. Using parametric models to estimate the hurricane field has become an important method in recent years. Early studies mostly assumed hurricanes or vortices with ideal symmetrical structures $[23,24]$. Therefore, the two-dimensional wind speed distributions simulated by these radial wind models are all axisymmetric. Nevertheless, hurricanes are rarely ideal symmetrical structures because of many factors, including frictional force dissipation, hurricane movement, vertical shear, environmental conditions, the near discontinuity of the surface friction and the latent heat flux, etc. [25]. In fact, the asymmetry of the wind field in azimuth is widespread. Highly asymmetric structures in a landfalling hurricane often led to large errors in storm surge forecasting [26]. Therefore, establishing asymmetric models to estimate hurricane winds remains a difficult yet crucial topic $[27,28]$.

In this study, an improved asymmetric hurricane parametric (IMAHP) model is proposed to estimate 2D wind speed, and high-resolution cross-polarized SAR data was used to determine the values of the model's parameters. The new model is mainly composed of two parts: (1) the tangential wind profile model proposed in [29] (henceforth M16) and (2) the improved azimuth asymmetry distribution mode (ASD) based on the M16 model. There are two main reasons for using this model structure: first, it has a relatively concise form of model function and directly uses the maximum wind speed as a model parameter to describe the hurricane intensity, and second, compared with the models based on the Rankine vortex, it can overcome the wind speed profile's unsmooth transition in the high wind speed area (near the eyewall), which makes the model simulation results consistent with the actual change of wind speed. For verification, taking SAR-retrieved wind speed as a reference, the root means square error (RMSE) and bias of the wind speed estimated by the IMAHP model was $1.86 \mathrm{~m} / \mathrm{s}, 1.89 \mathrm{~m} / \mathrm{s}$ for Hurricane Arthur (2014), $2.01 \mathrm{~m} / \mathrm{s}$, $1.77 \mathrm{~m} / \mathrm{s}$ for Hurricane Iselle (2014) and 1.99 m/s, 1.74 m/s for Hurricane Norbert (2014), respectively. Statistical results showed that the proposed IMAHP model performs better to capture the asymmetric distribution of hurricane winds and that its simulation results are closer to airborne measurements.

The main novelties associated to this research topic consisted of advancing the state of the art related to both wind speed estimation by SAR under extreme winds and to the modelling of hurricane structure. In both the cases, the use of SAR measurements was a key drive to provide reliable and effective estimates of the geophysical parameters of interest.

\section{Research Results and Conclusions}

\subsection{SARCO}

The most relevant results of the SARCO subtopics are here summarized.

\subsubsection{Results}

(1) Polarimetric SAR target detection in coastal areas 
In this piece of research, the monitoring of offshore wind farms by means of multipolarization SAR data is showcased. The Jiangsu Rudong offshore wind farm, a $150 \mathrm{MW}$ wind farm located off the coast of Rudong County (Jiangsu Province of East China), which is the largest offshore wind farm in China, was selected as study area. The wind farm consists of a large number (more than 50) of wind turbines installed over an intertidal flat. This makes their detection very challenging. A dual-polarimetric Sentinel-1 SAR image collected over the study area in interferometric wide swath mode under a vertical polarization transmission and $38^{\circ}$ incidence angle with $2 \mathrm{~m} \times 14 \mathrm{~m}$ pixel spacing was considered. The performance of different detectors was investigated using both $\mathrm{C}$ - and X-band multipolarization SAR scenes:

- $\quad$ single-pol (SP) detectors, including VV- and VH-polarized NRCSs;

- dual-pol detectors, including the PNF (1) and PMF (from (4)).

As a figure of merit for the detection performance, ROC was adopted, which method consists of plotting the detection probability versus the false alarm probability-which in turn is related to the threshold used to obtain the detection mask. Results are shown in Figure 2. As expected, the detection probability tended to 1 when increasing the false alarm rate. When dealing with SP detectors (VV-and VH-polarized NRCS are depicted in dashed yellow and dotted purple plots, respectively), they both achieved the best detection rate of about $90 \%$ (for a false alarm probability of about $17 \times 10^{-3}$ ), with the copolarized channel slightly outperforming the cross-polarized one. When dealing with dual-polarimetric detectors (the PNF and PMF are depicted in blue and dashed orange plots, respectively), they provided significantly better detection results if compared to the SP ones. In fact, their detection probability reached 1 at a false alarm rate of about $1.4 \times 10^{-4}$. The ROC shown in Figure 2 also shows that the PNF and PMF offered almost the same detection performance.

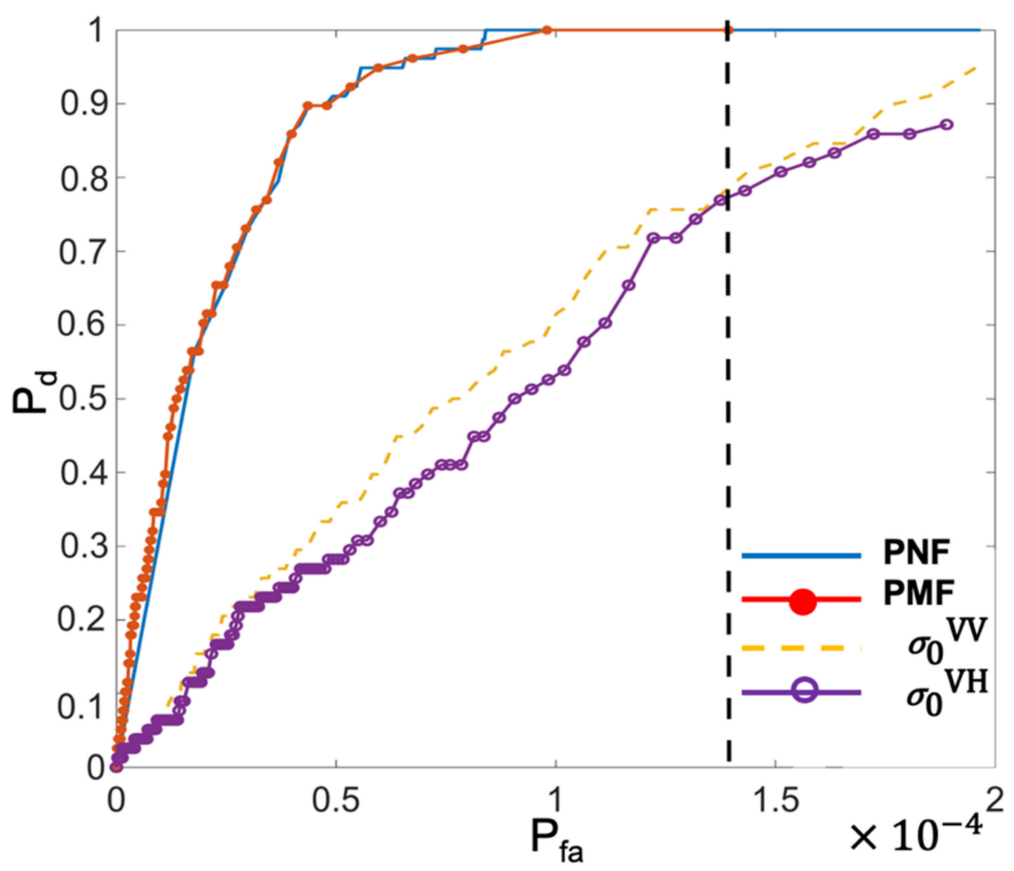

Figure 2. ROC curves relevant to the detection of wind turbines in Rudong (China) intertidal flats. The detection was performed by exploiting different polarimetric information (VV-and VH-polarized NRCSs and $2 \times 2$ covariance matrix) from a dual-polarimetric Sentinel-1 SAR image.

A more extensive experimental campaign was undertaken that included additional multipolarization SAR datasets, i.e., quad-polarimetric Radarsat-2 and dual-polarimetric copolarized TerraSAR-X imagery, and optimized detectors (see [10]). The ROC curves showed that: (i) with Radarsat-2 the best performance was obtained using full-pol mea- 
surement and the PMF, followed by the PNF applied to full-pol measurements; (ii) with TerraSAR-X (dual-pol data), the PNF and PMF provided the same performance.

(2) Extraction of the shoreline profile and generation of risk map from polarimetric SAR imagery

In this research, the observation of coastal areas, i.e., shoreline extraction and inland classification, using multipolarization SAR measurements is showcased. The coastal area of the Gibraltar Strait along the European side was selected as study area since it is characterized by particular sea state conditions and a composite coastal morphology that includes sandy beaches, urban settlements and vegetation. A quad-polarimetric Radarsat-2 SAR image collected over the study area at a $22^{\circ}$ incidence angle with $8 \mathrm{~m} \times 9 \mathrm{~m}$ spatial resolution is considered. Two different tasks of interest for an effective coastal management were accomplished, the results of which are shown in Figure 3:

- Shoreline extraction exploiting dual- $\left(r\right.$ metric in [5]) and quad- $\left(P_{S}\right.$ and $P_{V}$ in [6]) polarimetric information.

- Generation of the associated risk map, i.e., highlighting coastal areas where changes in the coastline can lead to property damage, loss of life and environmental degradation, from quad-polarimetric information $\left(P_{S}, P_{D B}\right.$ and $P_{V}$ in (6)).
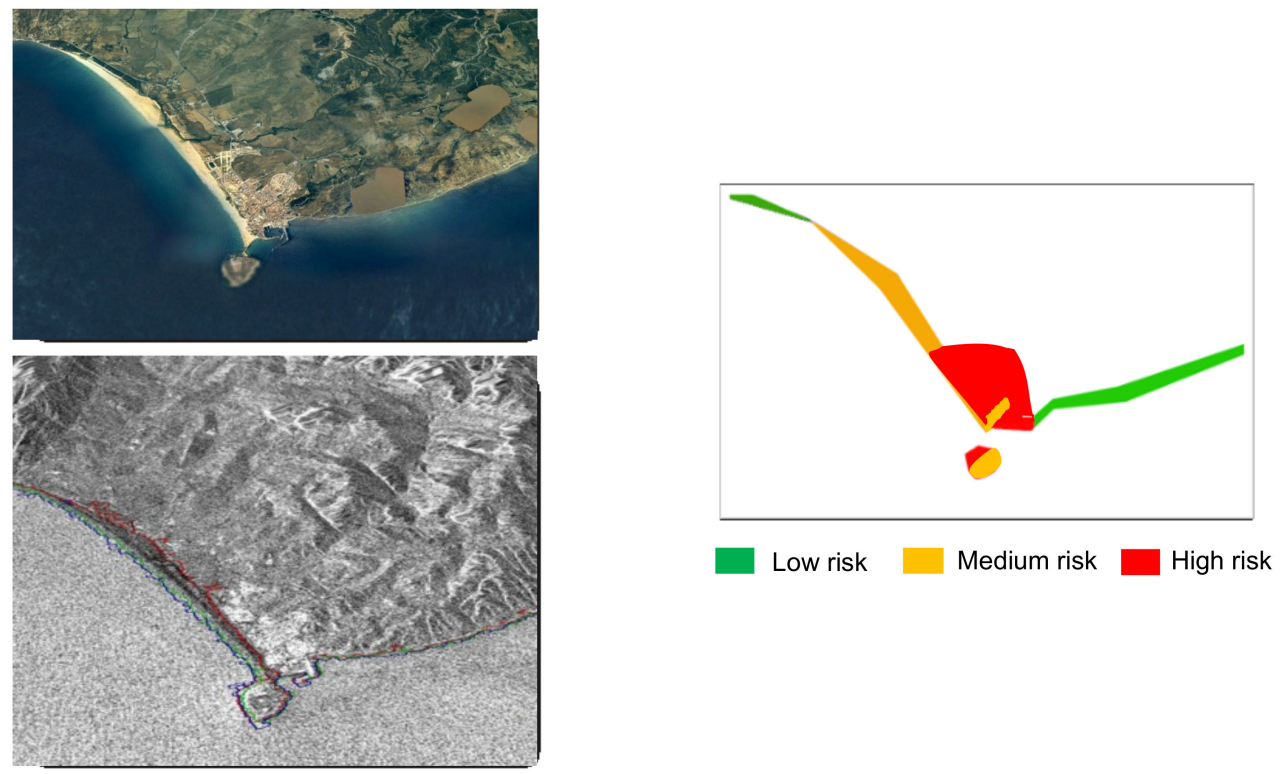

Figure 3. Shoreline and risk map obtained from a quad-polarimetric Radarsat-2 SAR image collected over the Gibraltar Strait. Top left: Google Earth $\odot$ optical image; bottom left: shorelines extracted from $r$ (red), see [5], Freeman-Durden model-based scattering components $P_{S}$ (green) and $P_{V}$ (blue), see [6], superimposed on the VV-polarized NRCS image; right: 3-class risk map generated from a decision-tree algorithm applied on the Freeman-Durden scattering components.

The extracted shorelines, superimposed on the original VV-polarized intensity image, are shown in red $(r)$, green $\left(P_{S}\right)$ and blue $\left(P_{V}\right)$. Results were analysed with respect to the corresponding Google Earth $\odot$ optical image, from which a shoreline was manually traced for reference purposes. All the polarimetric features allowed obtaining shorelines that well fit the actual coastal profile, even though the detection of sandy beaches is critical due to their polarimetric backscattering, which is similar to that of the sea surface. When dealing with the dual-polarimetric feature $r$, an average distance of $310 \mathrm{~m}$ was observed between the extracted and the reference shoreline, with the former results shifted towards the land with respect to the latter [30]. This is a satisfactory result considering that the sandy beaches extend from about $80 \mathrm{~m}$ to $360 \mathrm{~m}$. Better performance was achieved when considering the quad-polarimetric features $P_{S}$ and $P_{V}$, that resulted in average distances 
of $171 \mathrm{~m}$ and $232 \mathrm{~m}$, respectively. In this case, the shift of the extracted shorelines with respect to the reference one is towards the sea. The better performance of $P_{S}$ was likely due to the capability of the surface scattering component to better detect the sandy beach Hence, over the study area and among the considered polarimetric features, the surface scattering component of the Freeman-Durden model provided the best result in terms of shoreline accuracy.

Once the shoreline was extracted, a risk map was generated by applying a supervised decision tree algorithm to the scattering-based classification output obtained from the Freeman-Durden decomposition. Three risk levels were considered that corresponded to three different classes, where the highest risk was associated to the densest occurrence of double-bounce scattering, which is predominant over urban areas. Hence, they are identified:

- A low risk level (green in the map of Figure 3) was associated to coastal areas where there is no double-bounce scattering, e.g., sandy beaches, bare soils, etc.

- A high risk level (red in the map of Figure 3) was associated to coastal areas where the double-bounce scattering from dense urban areas is significant.

- A medium risk level (orange in the map of Figure 3) was associated to coastal areas where the presence of scatterers calling for a dominant double-bounce scattering is sparse.

\subsubsection{Conclusions}

In this piece of research, the team jointly cooperated to develop algorithms and methodologies to exploit multipolarization SAR measurements in the context of target detection at sea and coastal area risk analysis.

With respect to the detection of metallic targets at sea, the performance of state-of-theart multipolarization detectors was intercompared in a very challenging test case, namely wind turbines located in a large intertidal flat area. Experimental results showed that FP measurements always guaranteed the best performance independently of the polarimetric detector choice. In addition, wind turbines resulted in a nontrivial polarimetric scattering behaviour that, in contrast to what may be naively expected, cannot be simply described by a dominant double-bouncing mechanism.

With respect to the evaluation of the risk associated with coastal erosion, a processing chain that exploited multipolarization SAR data to (a) extract the coastline and (b) classify the inland area near the extracted coastline using the dominant scattering mechanism was developed and tested on actual SAR measurements. Experimental results showed the ability of polarimetric SAR measurements to assist policy makers though an added-value product that jointly shows the coastline and classifies the land use.

\subsection{SCOPeSAR}

\subsubsection{Results}

The most relevant results of the SCoPeSAR subtopic are here summarized.

In [8], we used Sentinel-1 images to enhance the capability of the PNF with an added processing step that performs a PCA before applying the PNF. The detection performance of the proposed PCA-PNF approach, analysed with three and six components to produce the initial feature vector, were compared, using the ROC metric, with that of several state-of-the-art detectors. The latter include both the single-pol detector based on the cross-polarized backscattering channel $(\mathrm{VH})$ and dual-pol detectors such as the standard PNF (1), $r$ (5) and those based on the RS and degree of depolarization (DoD). Experimental results showed that the PCA version of the PNF produced the best results, obtaining a probability of detection close to 1 with a false alarm rate of about $10^{-4}$.

In [9], we used TerraSAR-X SAR images to model the backscattering of oil rigs and detect them. Figure 4 shows a sketch of the model used, where the different scattering mechanisms can be easily identified in high resolution images. We compared the following detectors: PNF, DoD, ratio and product of copolarization channels. Depending on the type 
of clutter, the best results were provided by PNF and DoD, with the former outperforming DoD under low-clutter conditions.

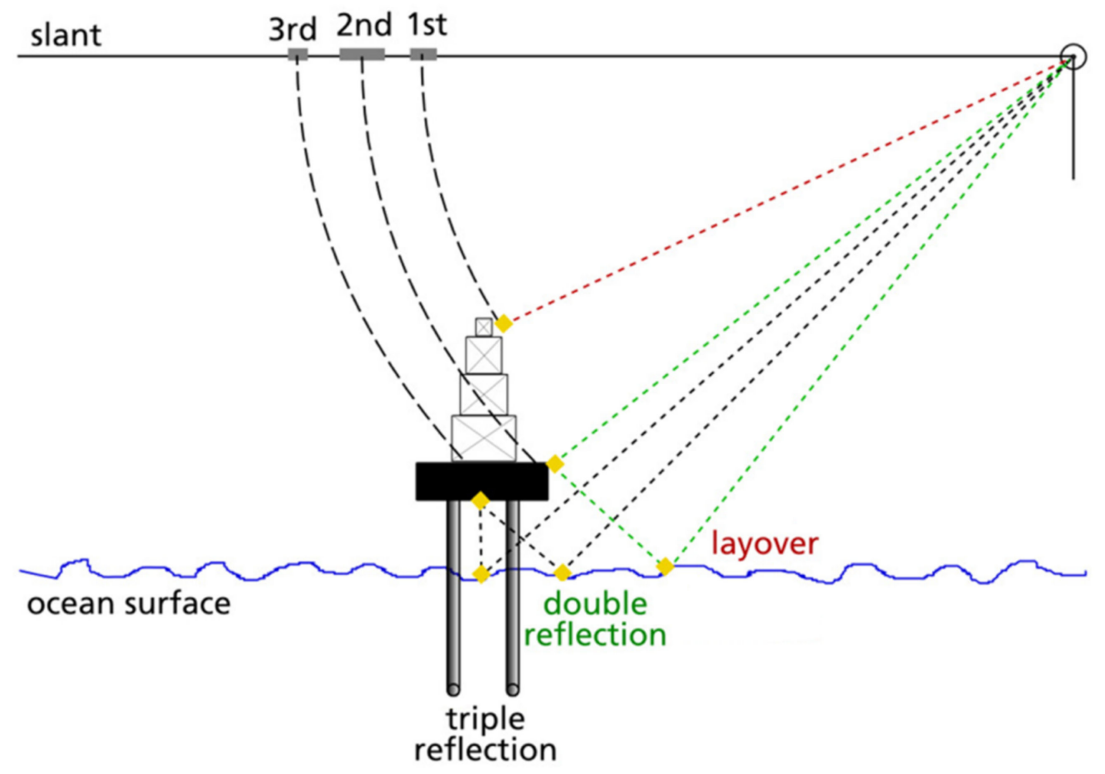

Figure 4. Sketch of the model used to identify the scattering mechanisms for oil rigs.

In $[12,13]$, we analysed more than 60 Sentinel-1 images acquired in the Atlantic gyros and identified several situations in which surfactants where visible. Figure 5 shows an example of the surfactant visible in images. To prove that these were not related to algal blooms, we collected chlorophyll-a data using Ocean Colour products. The level of chlorophyll was very low, and therefore, it could not have been the cause of the observed surfactants. We hypothesized that these surfactants are related to microbial activity of microbes colonizing the microplastic.

\subsubsection{Conclusions}

In the framework of the Dragon-4 collaboration, we performed work to improve our understanding of target detection at sea. We developed a new ship detection methodology that proved to provide superior performance with respect to previous algorithms. We modelled the backscattering of artificial targets often located in coastal areas, namely oil rigs and wind turbines. This novel research aimed at developing capabilities for the monitoring of these structures, which are becoming more present in our coastal environment. We also worked on a novel idea for detecting microplastic in the oceans by looking at the surfactants produce by the microbial communities living on the plastic.

For future work, we aim to continue developing new methodologies able to detect targets at sea that can exploit the new generation of satellites available in the coming years. We also aim to gain a better understanding of microplastic backscattering to improve our capability to detect this emerging pollutant.

\subsection{SHENLONG}

The most relevant results of the SHENLONG subtopic are here summarized.

\subsubsection{Results}

In this piece of research related to the tuning of the SAR azimuth cutoff to estimate wind speed under extreme weather events we discuss a case study that refers to Hurricane Hermine, which struck the coast of Florida, U.S., on 2 September 2016. Hurricane Hermine, classified as category 1 , formed on 28 August and, after reaching extremely high winds, i.e., up to $36 \mathrm{~m} / \mathrm{s}$, dissipated on 8 September. It resulted in dramatic aftermaths, with more than 500 million U.S. dollars of damages and four fatalities. The azimuth cutoff 
approach (see [7] and [8]) was applied on a VV-polarized Sentinel-1 SAR image collected in the interferometric wide swath mode during the extreme weather event, whose results are shown in Figure 6 (left). Large $\lambda_{c}$ values, i.e., up to $400 \mathrm{~m}$, were observed over the sea surface area affected by the hurricane (see the eastern part of the study area, result in an average wind speed value of about $20 \mathrm{~m} / \mathrm{s}$ ). The reliability of the results was confirmed by the QC procedure, which showed $\chi^{2}$ test values lower than 0.06 . The effectiveness of the proposed approach was confirmed by the high degree of correlation-about 0.9 -with the wind speed estimated according to an independent SAR-based method proposed in [31], the image of which is shown in Figure 6 (right).

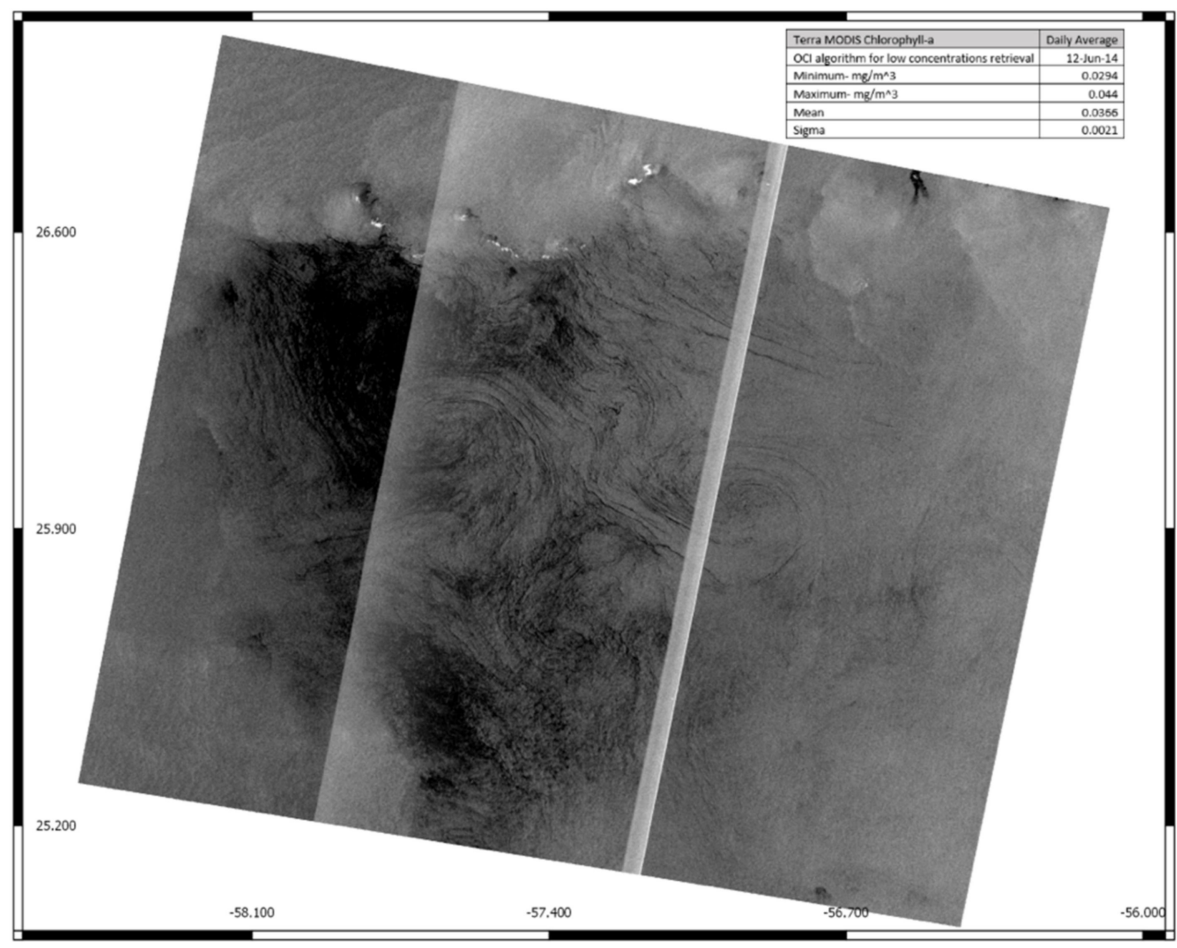

Figure 5. Sentinel-1A SAR image collected on 12 June 2014-09:43, with dark stripes attributed to surfactants.
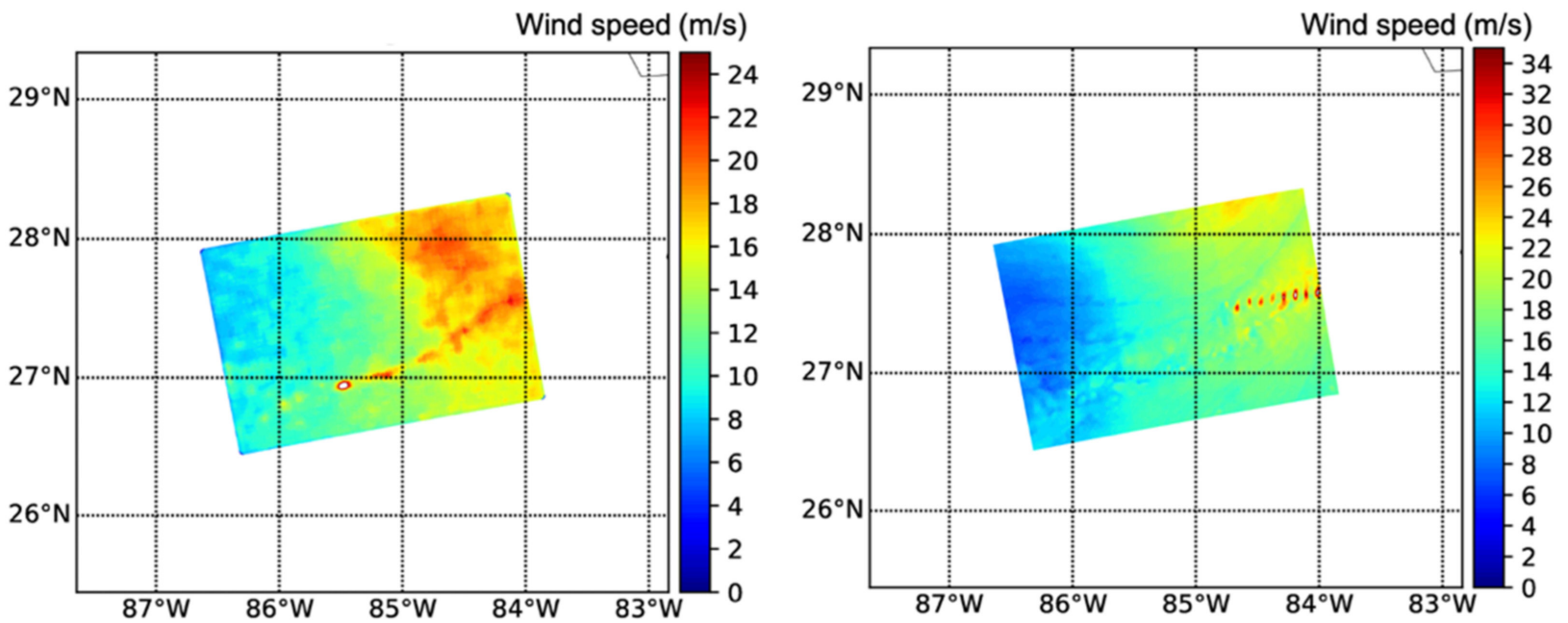

Figure 6. Wind speed map obtained from a VV-polarized Sentinel-1A SAR image during the Hermine cyclone according to the azimuth cutoff approach (left) and the method proposed in [31] (right). 
In this research, related to the Asymmetric Hurricane Parametric Model based on cross-pol SAR observations, we used the IMAHP model to estimate 2D wind speed, and high-resolution cross-polarized C-band Radarsat-2 ScanSAR wide SAR data was used to determine the values of model parameters (see Figure 7). For verification, taking SARretrieved wind speed as a reference, the root means square error (RMSE) and bias of the wind speed estimated by the IMAHP model was $1.86 \mathrm{~m} / \mathrm{s}, 1.89 \mathrm{~m} / \mathrm{s}$ for Hurricane Arthur (2014), $2.01 \mathrm{~m} / \mathrm{s}, 1.77 \mathrm{~m} / \mathrm{s}$ for Hurricane Iselle (2014) and $1.99 \mathrm{~m} / \mathrm{s}, 1.74 \mathrm{~m} / \mathrm{s}$ for Hurricane Norbert (2014), respectively. Statistics results showed that the proposed IMAHP model performed better to capture the asymmetric distribution of hurricane winds, and its simulation results were closer with airborne measurements.

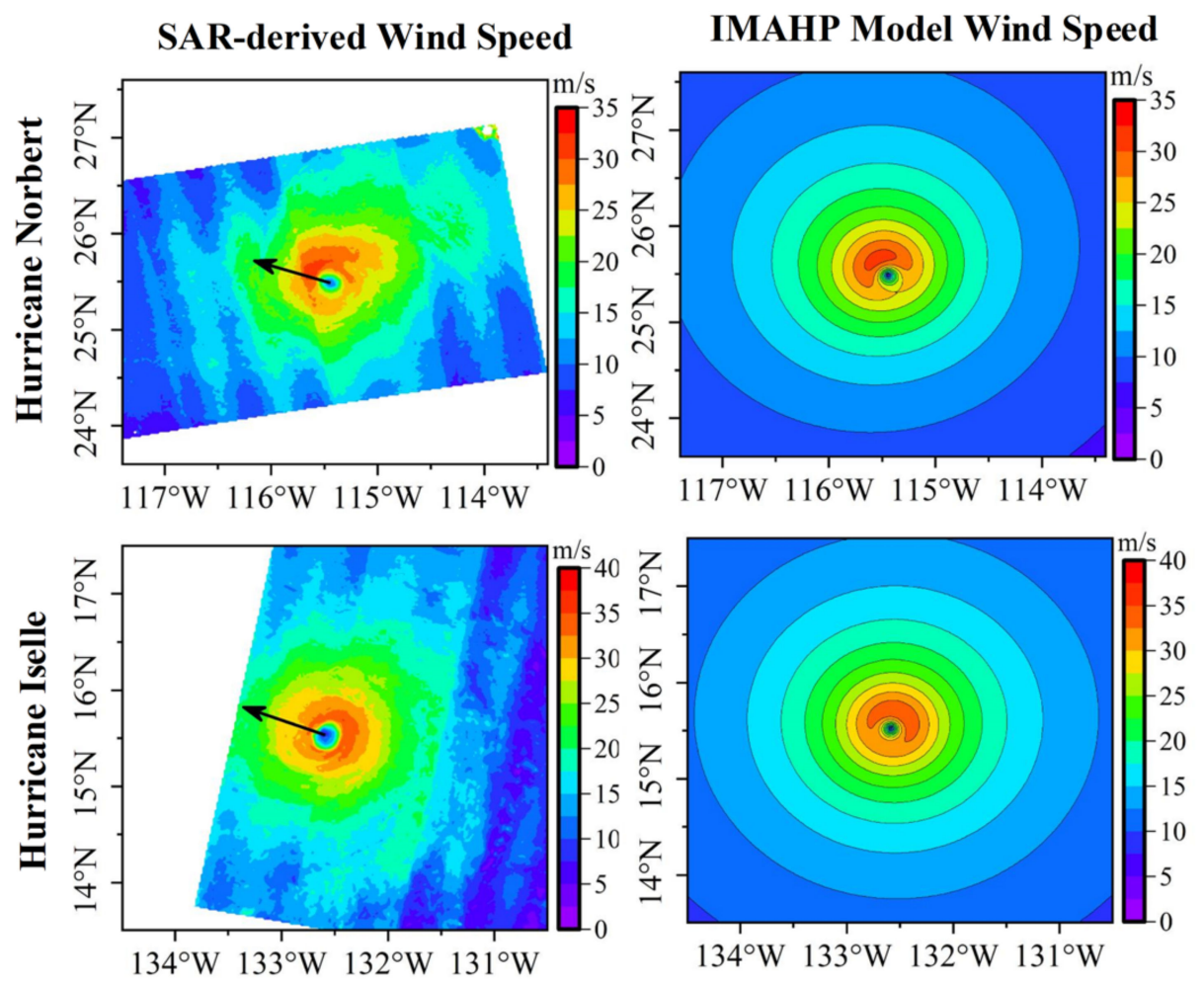

Figure 7. The distribution of 2D wind speed derived by SAR (left) and simulated by the IMAHP model (right). The black arrows indicate the direction of movement of the hurricanes, which were calculated from the best track data.

\subsubsection{Conclusions}

In this subtopic, we proposed two new methods to improve the estimation of tropical cyclone winds from spaceborne SAR observations. First, the azimuth cutoff method, typically used for SAR moderate wind speed estimation purposes, was analysed under high wind regimes. This analysis revealed the importance of filtering out unreliable and unfeasible azimuth cutoff values to improve the wind speed estimation. The QC procedure was based on a $\chi^{2}$ test, applied on a large Sentinel-1A dataset. The soundness of the test was verified by an increment in terms of correlation between $\lambda_{c}$ estimations and wind speed values. This approach was applied under high wind regimes, and the results seemed to be very consistent when compared with wind speed maps provided from external sources in some areas. In particular, an analysis carried out on the inverse wave age parameter showed that the values sorted out by the QC analysis were in correspondence with mixed sea state conditions, and, therefore, the more critical scenarios take place with the presence of the swell contribution.

Secondly, an asymmetric hurricane parametric model was proposed to estimate the hurricane wind speed distribution. In this parametric model, we simplified the model function using the tangential winds model, and cross-polarized SAR observations were 
selected to determine the model parameters. Comparisons with other existing hurricane models under different hurricane cases showed that the proposed model performs better to capture the asymmetric distribution of hurricane winds and that its simulation results are closer with airborne measurements.

\section{Overall Discussion}

The joint work performed by EU and Chinese teams under the Dragon- 4 cooperation framework was based on the intelligent processing of multipolarization SAR measurements to generate added-value products in the context of coastal area observation also under extreme weather conditions.

The scientific relevance of the obtained results is twofold: on one side, new methods were developed and verified on actual SAR measurements; on the other side, existing methodologies were advanced and intercompared using challenging test cases. In both cases, a synergistic approach to deal with coastal area management is proposed to stimulate research in thematic areas such as multipolarization sea surface scattering, data fusion among different sensors, sea surface scattering under extreme wind conditions, etc. In addition, added-value products, e.g., maps of metallic targets at sea, coastlines, water pollution maps and typhoon/cyclone monitoring, which form the basis of effective coastal area management for the end-user community, were provided.

The Dragon- 4 cooperation stimulated scientific exchange by the formation of joint Sino-European teams that, characterized by complementary expertise, included young scientists. This cooperation resulted in coauthored publications in leading scientific journals and paved the way to a future cooperation focused on some challenging subjects, e.g., SAR estimation of wind fields under extreme events and observation of marine pollution using a synergistic approach that jointly combines SAR and optical measurements.

\section{Main Conclusions}

The joint research activities carried out within the frame of the ESA-MOST Dragon-4 project resulted in the publication of 40 papers that appeared in peer-reviewed international journal papers and proceedings of international conferences (see Figure 8).

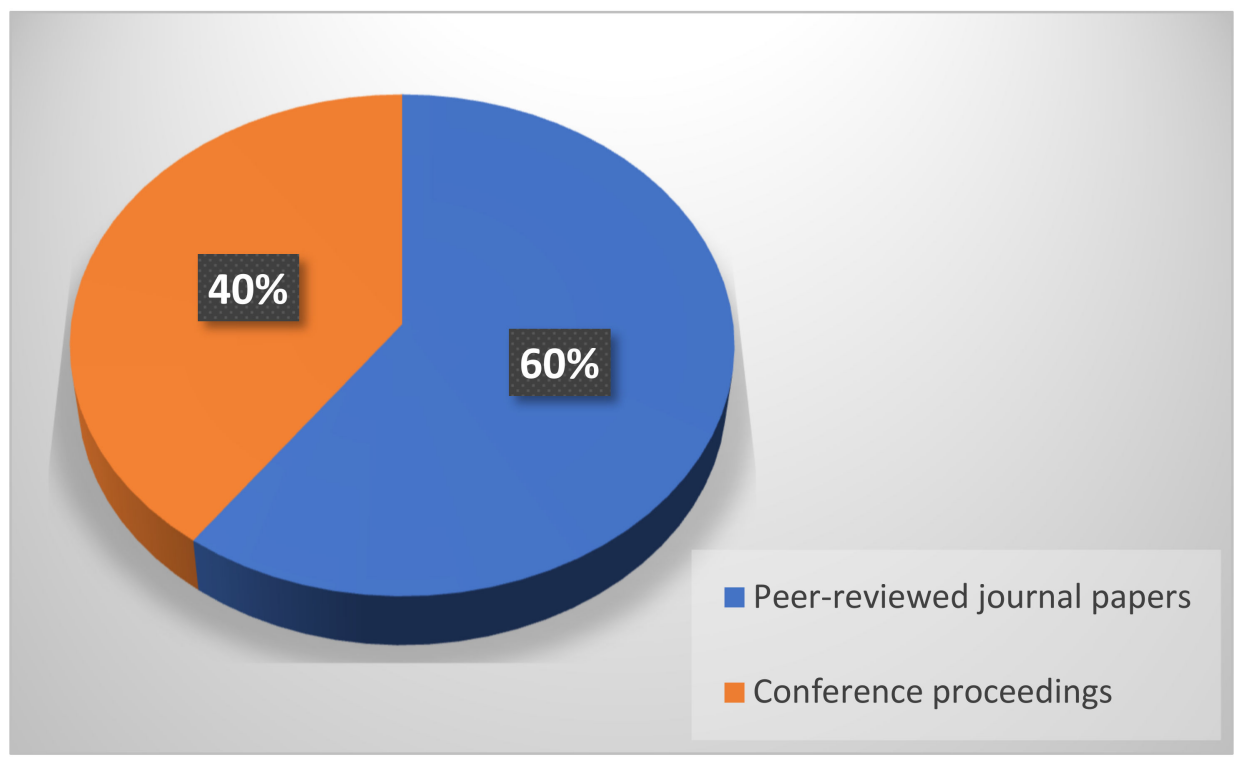

Figure 8. Project outcomes included 40 published papers related to the ESA-MOST Dragon-4 project research activities, 24 of which were peer-reviewed journal papers and 16 of which were international conference proceedings.

The complete list of peer-reviewed journal papers published under the ESA-MOST Dragon-4 project is as follows: 
(1) V. Corcione, F. Nunziata, M. Portabella, G. Grieco, X. Yang, and M. Migliaccio, "SAR Azimuth Cut-off to Estimate Wind Speed under High Wind Regimes," Chinese Journal of Geodesy and Geoinformation Science, vol. 4. no.1, pp. 30-37, 2021.

(2) A. Buono, C. R. de Macedo, F. Nunziata, D. Velotto, and X. Li, "The Taylor Energy oil spill: time-series of polSAR data to support continuous and effective observation", Chinese Journal of Geodesy and Geoinformation Science, vol. 4. no.1, pp. 24-29, 2021.

(3) T. Zhang, A. Marino, F. Nunziata, D. Velotto, W. Shao, X. Li, M. Migliaccio, and H. Xiong, "Marine Target Detection Using Dual-polarimetric SAR Imagery," Chinese Journal of Geodesy and Geoinformation Science, vol. 4. no.1, pp. 63-69, 2021.

(4) E. Ferrentino, F. Nunziata, A. Buono, A. Urciuoli and M. Migliaccio, "Multipolarization Time Series of Sentinel-1 SAR Imagery to Analyze Variations of Reservoirs' Water Body," IEEE Journal of Selected Topics In Applied Earth Observations And Remote Sensing, vol. 13, pp. 840-846, 2020.

(5) E. Ferrentino, F. Nunziata, A. Marino, M. Migliaccio and X. Li, "Detection of wind turbines in intertidal areas using SAR polarimetry," IEEE Geoscience and Remote Sensing Letters, vol. 16, no. 10, pp. 1516-1520, 2019.

(6) M. Migliaccio, L. Huang and A. Buono, "SAR speckle dependence on ocean wind field," IEEE Transactions on Geoscience and Remote Sensing, vol. 57, no. 8, pp. 5447-5455, 2019.

(7) S. Zhu, W. Shao, A. Marino, J. Shi, J. Sun, X. Yuan, J. Hu, D. Yang and J. Zuo, "Evaluation of Chinese quad-polarization Gaofen-3 SAR wave mode data for wave retrieval," Canadian Journal of Remote Sensing, vol. 44, no. 6, pp. 588-600, 2019.

(8) W. Shao, S. Zhu, J. Sun, X. Yuan, Y. Sheng, Q. Zhang and Q. Ji, “Evaluation of Wind Retrieval from Co-Polarization Gaofen-3 SAR Imagery Around China Seas," Journal of Ocean University of China, vol. 18, pp. 80-92, 2019.

(9) D. Di Luccio, G. Benassai, G. Di Paola, L. Mucerino, A. Buono, C. M. Rosskopf, F. Nunziata, M. Migliaccio, A. Urciuoli and R. Montella, "Shoreline Rotation Analysis of Embayed Beaches by Means of In Situ and Remote Surveys," Sustainability, vol. 11, no. 3, pp. 725-745, 2019.

(10) F. Nunziata, C. R. de Macedo, A. Buono, D. Velotto and M. Migliaccio, “On the analysis of a time series of X-band TerraSAR-X SAR imagery over oil seepages," International Journal of Remote Sensing, vol. 49, no. 9, pp. 3623-3646, 2019.

(11) A. Buono, F. Nunziata, C. R. De Macedo, D. Velotto and M. Migliaccio, "A sensitivity analysis of the standard deviation of the co-polarized phase difference for sea oil slick observation," IEEE Transaction on Geoscience and Remote Sensing, vol. 57, no. 4, pp. 2022-2030, 2019.

(12) V. Corcione, G. Grieco, M. Portabella, F. Nunziata and M. Migliaccio, "A novel azimuth cut-off implementation to retrieve sea surface wind speed from SAR imagery," IEEE Transactions on Geoscience and Remote Sensing, vol. 57, no. 6, pp. 3331-3340, 2018.

(13) T. Zhang, A. Marino, H. Xiong and W. Yu, "A Ship Detector Applying Principal Component Analysis to the Polarimetric Notch Filter," Remote Sensing, vol. 11, no. 6, pp. 948, 2018.

(14) W. Shao, X. Yuan, Y. Sheng, J. Sun, W. Zhou and Q. Zhang, “Development of wind speed retrieval from cross-polarization Chinese Gaofen-3 synthetic aperture radar in typhoons," Sensors, vol. 18, no. 2, pp. 412, 2018.

(15) A. Buono, C. R. De Macedo, F. Nunziata, D. Velotto and M. Migliaccio, "Analysis on the effects of SAR imaging parameters and environmental conditions on the standard deviation of the co-polarized phase difference measured over sea surface," Remote Sensing, vol. 11, no. 1, pp. 18-33, 2018.

(16) F. Nunziata, A. Buono and M. Migliaccio, "COSMO-SkyMed Synthetic Aperture Radar Data to Observe the Deepwater Horizon Oil Spill," Sustainability, vol. 10, n. 3599, 2018.

(17) W. Shao, Y. Hu, J. Yang, F. Nunziata, J. Sun, H. Li and J. Zuo, “An Empirical Algorithm to Retrieve Significant Wave Height from Sentinel-1 Synthetic Aperture Radar Imagery 
Collected under Cyclonic Conditions," Remote Sensing, vol. 10, n. 9, pp. 1367-1384, 2018.

(18) G. Benassai, D. Di Luccio, V. Corcione, F. Nunziata and M. Migliaccio, "Marine Spatial Planning using high resolution SAR measurements," IEEE Journal of Oceanic Engineering, vol. 43, no. 3, pp. 586-594, 2018.

(19) A. Marino, D. Velotto and F. Nunziata, "Offshore platforms observation using dualpolarimetric TS-X/TD-X satellite imagery: a case study in the Gulf of Mexico," IEEE Journal of Selected Topics in Applied Earth Observation and Remote Sensing, vol. 43, no. 1, pp. 184-194, 2018.

(20) Q. Ji, W. Shao, Y. Sheng, X. Yuan, J. Sun, W. Zhou and J. Zuo, "A promising method of typhoon wave retrieval from Gaofen-3 synthetic aperture radar image in VVpolarization," Sensors, vol. 18, no. 7, pp. 2064, 2018.

(21) Y. Sheng, W. Shao, S. Zhu, J. Sun, X. Yuan, S. Li, J. Shi and J. Zuo, "Validation of significant wave height retrieval from co-polarization Chinese Gaofen-3 SAR imagery using an improved algorithm," Acta Oceanologica Sinica, vol. 37, pp. 1-10, 2018.

(22) W. Shao, Y. Sheng and J. Sun, "Preliminary Assessment of wind and wave retrieval from Chinese Gaofen-3 SAR imagery," Sensors, vol. 17, no. 8, pp. 1705, 2017.

(23) E. Ferrentino, F. Nunziata and M. Migliaccio, "Full-polarimetric SAR measurements for coastline extraction and coastal area classification," International Journal of Remote Sensing, vol. 38, n. 23, pp. 7405-7421, 2017.

(24) A. Buono, F. Nunziata, M. Migliaccio, X. Yang and X. Li, "Classification of the Yellow River delta area using fully polarimetric SAR measurements," International Journal of Remote Sensing, vol. 38, n. 23, pp. 6714-6734, 2017.

The complete list of conference proceedings published under the ESA-MOST Dragon4 project can be found as follows:

(1) X. Yang, X. Li, M. Portabella, W. Zhang, “Assimilation of Satellite Remotely Sensed Surface Winds for Typhoon Forecasting: Progress and Perspective," Proceedings of the 11th International Symposium on Digital Earth, September 24-27, Florence, Italy, 2019.

(2) M. Migliaccio, A. Buono, L. Huang and F.Nunziata, "On the relationship between sea surface SAR speckle and wind field," Proceedings of IEEE Oceans 2019, 17-20 June, Marseille, France, 2019.

(3) F. Nunziata, A. Buono, M. Migliaccio, G. Benassai, D. Di Luccio, "Shoreline erosion of microtidal beaches examined with UAV and remote sensing techniques," Proceedings of the 2018 IEEE International Workshop on Metrology for the Sea, October 8-10, Bari, Italy, 2018.

(4) L. Huang, A. Buono and M. Migliaccio, "SAR speckle as a proxy of sea surface wind speed," Proceedings of the 7th IEEE/OES Baltic Symposium, Klaipèda, Lithuania, June 12-15, 2018.

(5) F. Nunziata, C. R. de Macedo, A. Buono, D. Velotto and M. Migliaccio, "On the effects of acquisition parameters and surface properties in sea oil seep observation by means of high-resolution SAR," Proceedings of IEEE IGARSS 2018, Valencia, Spain, July 23-27, 2018.

(6) F. Nunziata, A. Urciuoli, A. Gifuni and M. Migliaccio, "A controlled environment to analyze polarimetric features for radar remote sensing purposes," Proceedings of IEEE IGARSS 2018, Valencia, Spain, July 23-27, 2018.

(7) A. Buono, F. Nunziata, M. Migliaccio, X. Yang and X. Li, "Polarimetric information for multi-frequency SAR classification of heterogeneous coastal regions," Proceedings of IEEE IGARSS 2018, Valencia, Spain, July 23-27, 2018.

(8) C. R. de Macedo, A. Buono, F. Nunziata, D. Velotto, and M. Migliaccio, "Sea oil seep monitoring using a time series of co-polarized coherent SAR measurements," Proceedings of IEEE IGARSS 2018, Valencia, Spain, July 23-27, 2018. 
(9) X. Yang, V. Corcione, F. Nunziata, M. Portabella and M. Migliaccio, "Assimilation of SAR-derived sea surface winds into typhoon forecast model," Proceedings of IEEE IGARSS 2018, Valencia, Spain, July 23-27, 2018.

(10) V. Corcione, G. Grieco, M. Portabella, F. Nunziata and M. Migliaccio "A new azimuth cut-off procedure to retrieve significant wave height under high wind regimes," Proceedings of IEEE IGARSS 2018, Valencia, Spain, July 23-27, 2018.

(11) N. Davaasuren, A. Marino, C. Boardman, M. Alparone and F. Nunziata, "Detecting microplastics pollution in world oceans using sar remote sensing" Proceedings of IEEE IGARSS 2018, Valencia, Spain, July 23-27, 2018.

(12) E. Ferrentino, A. Marino, F. Nunziata, M. Migliaccio and X. Li, "Multi-polarization methods to detect mud flat areas using C- and X-band spaceborne SAR data," Proceedings of ESA SeaSAR 2018, Frascati, Italy, May 7-10, 2018.

(13) K. Horiya, A. Buono, F. Nunziata, D. Velotto, M. Migliaccio and Y. Smara, "Analysis of the Oil Seep-affected Sea Surface Microwave Backscattering," Proceedings of ESA SeaSAR 2018, Frascati, Italy, May 7-10, 2018.

(14) N. Davaasuren, A. Marino, C. Boardman, M. Alparone and F. Nunziata, "Exploring the use of SAR remote sensing to detect microplastics pollution in the oceans," Proceedings of ESA SeaSAR 2018, Frascati, Italy, May 7-10, 2018.

(15) V. Corcione, F. Nunziata, G. Grieco, M. Portabella and M. Migliaccio, "The Azimuth Cut-Off Method to Estimate Wind Speed under Extreme Weather Conditions," SeaSAR 2018, Rome, Italy, May 7-10, 2018.

(16) T. Zhang, A. Marino and H. Xiong, "A ship detector applying principal component analysis to the polarimetric notch filter," Proceedings of IEEE IGARSS 2017, Fort Worth, USA, July 23-28, 2017.

Author Contributions: Conceptualization, F.N. and X.L.; methodology, A.M., W.S., M.P., X.Y. and A.B., investigation, A.M., W.S., M.P., X.Y. and A.B.; data curation, A.M., W.S., M.P., X.Y. and A.B.; writing-original draft preparation, A.M., W.S., M.P., X.Y. and A.B.; writing-review and editing, F.N. and X.L.; supervision, F.N. and X.L.; project administration, F.N. and X.L. All authors have read and agreed to the published version of the manuscript.

Funding: This research was funded by the ESA-MOST Dragon-4 project "Microwave satellite measurements for coastal area and extreme weather monitoring", grant number 32235. The APC was funded by the ESA and NRSCC.

Institutional Review Board Statement: Not applicable.

Informed Consent Statement: Not applicable.

Acknowledgments: We would like to acknowledge the Dragon-4 coordinators and all the members and volunteers of the team in charge of symposium organization.

Conflicts of Interest: The authors declare no conflict of interest. The funders had no role in the design of the study; in the collection, analyses, or interpretation of data; in the writing of the manuscript; or in the decision to publish the results.

\section{References}

1. Marino, A. A notch filter for ship detection with polarimetric SAR data. IEEE J. Sel. Top. Appl. Earth Observ. Remote Sens. 2013, 6, 1219-1232. [CrossRef]

2. Novak, L.M.; Sechtin, M.B.; Cardullo, M.J. Studies of target detection algorithms that use polarimetric radar data. IEEE Trans. Aerosp. Electron. Syst. 1989, 25, 150-165. [CrossRef]

3. Marino, A.; Hajnsek, I. A change detector based on an optimization with polarimetric SAR imagery. IEEE Trans. Geosci. Remote Sens. 2014, 52, 4781-4798. [CrossRef]

4. Nunziata, F.; Buono, A.; Migliaccio, M.; Benassai, G. Dual-Polarimetric C- and X-Band SAR Data for Coastline Extraction. IEEE J. Sel. Topics Appl. Earth Observ. Remote Sens. 2016, 9, 4921-4928. [CrossRef]

5. Ferrentino, E.; Nunziata, F.; Buono, A.; Urciuoli, A.; Migliaccio, M. Multipolarization Time Series of Sentinel-1 SAR Imagery to Analyze Variations of Reservoirs' Water Body. IEEE J. Sel. Topics Appl. Earth Observ. Remote Sens. 2020, 13, 840-846.

6. Freeman, A.; Durden, S.L. A three-component scattering model for polarimetric SAR data. IEEE Trans. Geosci. Remote Sens. 1998, 36, 963-973. [CrossRef] 
7. Nunziata, F.; Migliaccio, M.; Brown, C.E. Reflection Symmetry for Polarimetric Observation of Man-Made Metallic Targets at Sea. IEEE J. Ocean. Engin. 2012, 37, 384-394. [CrossRef]

8. Zhang, T.; Marino, A.; Xiong, H.; Yu, W. A Ship Detector Applying Principal Component Analysis to the Polarimetric Notch Filter. Remote Sens. 2018, 11, 948. [CrossRef]

9. Marino, A.; Velotto, D.; Nunziata, F. Offshore platforms observation using dual-polarimetric TS-X/TD-X satellite imagery: A case study in the Gulf of Mexico. IEEE J. Sel. Topics Appl. Earth Observ. Remote Sens. 2018, 43, 184-194. [CrossRef]

10. Ferrentino, E.; Nunziata, F.; Marino, A.; Migliaccio, M.; Li, X. Detection of wind turbines in intertidal areas using SAR polarimetry. IEEE Geosci. Remote Sens. Lett. 2019, 16, 1516-1520. [CrossRef]

11. Ferrentino, E.; Marino, A.; Nunziata, F.; Migliaccio, M.; Li, X. Multi-polarization methods to detect mud flat areas using C- and X-band spaceborne SAR data. In Proceedings of the 5th Advances in SAR Oceanography Workshop (SeaSAR 2018), Frascati, Italy, 7-11 May 2018.

12. Davaasuren, N.; Marino, A.; Boardman, C.; Alparone, M.; Nunziata, F. Detecting microplastics pollution in world oceans using sar remote sensing. In Proceedings of the IGARSS 2018 IEEE International Geoscience and Remote Sensing Symposium, Valencia, Spain, 22-27 July 2018.

13. Davaasuren, N.; Marino, A.; Boardman, C.; Alparone, M.; Nunziata, F. Exploring the use of SAR remote sensing to detect microplastics pollution in the oceans. In Proceedings of the 5th Advances in SAR Oceanography Workshop (SeaSAR 2018), Frascati, Italy, 7-11 May 2018.

14. Migliaccio, M.; Huang, L.; Buono, A. SAR Speckle Dependence on Ocean Surface Wind Field. IEEE Trans. Geosci. Remote Sens. 2019, 57, 5447-5455. [CrossRef]

15. Corcione, V.; Grieco, G.; Portabella, M.; Nunziata, F.; Migliaccio, M. A novel azimuth cut-off implementation to retrieve sea surface wind speed from SAR imagery. IEEE Trans. Geosci. Remote Sens. 2018, 57, 3331-3340. [CrossRef]

16. Kerbaol, V.; Chapron, B.; Vachon, P.W. Analysis of ERS-1/2 synthetic aperture radar wave mode imagettes. J. Geophys. Res. Ocean. 1998, 103, 7833-7846. [CrossRef]

17. Vickery, P.J.; Masters, F.J.; Powell, M.D.; Wadhera, D. Powell. Hurricane hazard modeling: The past, present, and future. J. Wind Eng. Ind. Aerodyn. 2009, 97, 392-405. [CrossRef]

18. Krien, Y.; Arnaud, G.; Cécé, R.; Ruf, C.; Belmadani, A. Can We Improve Parametric Cyclonic Wind Fields Using Recent Satellite Remote Sensing Data? Remote Sens. 2018, 10, 1963. [CrossRef]

19. Li, X.; Zhang, J.A.; Yang, X.; Pichel, W.G.; DeMaria, M.; Long, D.; Li, Z. Tropical cyclone morphology from spaceborne synthetic aperture radar. Bull. Am. Meteor. Soc. 2013, 94, 215-230. [CrossRef]

20. Shao, W.; Li, X.; Hwang, P.A.; Zhang, B.; Yang, X. Bridging the gap between cyclone wind and wave by C-band SAR measurements. J. Geophys. Res. Oceans 2017, 122, 6714-6724. [CrossRef]

21. Zhang, G.; Li, X.; Perrie, W.; Hwang, P.A.; Zhang, B.; Yang, X. A Hurricane Wind Speed Retrieval Model for C-Band RADARSAT-2 Cross-Polarization ScanSAR Images. IEEE Trans. Geosci. Remote Sens. 2017, 55, 4766-4774. [CrossRef]

22. Holland, G.J. An analytic model of the wind and pressure profiles in hurricanes. Mon. Weather Rev. 1980, 108, 1212-1218. [CrossRef]

23. Wood, V.T.; White, L.W. A New Parametric Model of Vortex Tangential-Wind Profiles: Development, Testing, and Verification. J. Atmos. Sci. 2011, 68, 990-1006. [CrossRef]

24. Wang, S.; Toumi, R.; Czaja, A.; Kan, A.V. An analytic model of tropical cyclone wind profiles. Q. J. R. Meteorol. Soc. 2015, 141, 3018-3029. [CrossRef]

25. Klotz, B.W.; Jiang, H. Examination of Surface Wind Asymmetries in Tropical Cyclones. Part I: General Structure and Wind Shear Impacts. Mon. Weather Rev. 2017, 145, 3989-4009. [CrossRef]

26. Xie, L.; Bao, S.W.; Pietrafesa, L.J.; Foley, K.; Fuentes, M. A real-time hurricane surface wind forecasting model: Formulation and verification. Mon. Weather Rev. 2006, 134, 1355-1370. [CrossRef]

27. Zhou, X.; Yang, X.; Li, Z.; Yu, Y.; Bi, H.; Ma, S.; Li, X. Estimation of tropical cyclone parameters and wind fields from SAR images. Sci. China Earth Sci. 2013, 56, 1977-1987. [CrossRef]

28. Zhang, G.S.; Perrie, W.; Li, X.; Zhang, J.A. A hurricane morphology and sea surface wind vector estimation model based on C-Band cross-polarization SAR imagery. IEEE Trans. Geosci. Remote Sens. 2017, 55, 1743-1751. [CrossRef]

29. Murty, P.L.N.; Bhaskaran, P.K.; Gayathri, R.; Sahoo, B.; Kumar, T.S.; SubbaReddy, B. Numerical study of coastal hydrodynamics using a coupled model for Hudhud cyclone in the Bay of Bengal. Estuar. Coast. Shelf Sci. 2016, 183, 13-27. [CrossRef]

30. Di Luccio, D.; Benassai, G.; Di Paola, G.; Mucerino, L.; Buono, A.; Rosskopf, C.M.; Nunziata, F.; Migliaccio, M.; Urciuoli, A.; Montella, R. Shoreline Rotation Analysis of Embayed Beaches by Means of In Situ and Remote Surveys. Sustainability 2019, 11, 725. [CrossRef]

31. Mouche, A.A.; Chapron, B.; Zhang, B.; Husson, R. Combined co-and cross-polarized SAR measurements under extreme wind conditions. IEEE Trans. Geosci. Remote Sens. 2017, 55, 6746-6755. [CrossRef] 